\title{
Humillados y ofendidos. Crítica conservadora al Olimpo Radical desde la prensa y la caricatura política de Alberto Urdaneta en los Estados Unidos de Colombia
}

Humillated and Offended. Conservative's Criticism to the Olimpo Radical from the Press and the Political Caricature of Alberto Urdaneta in the Estados Unidos de Colombia

\section{Jacobo Santos Gómez*}

\section{Resumen}

Este artículo se centra en el análisis de la prensa del siglo XIX colombiano, específicamente, en los Estados Unidos de Colombia, 1863-1885. Se pretende estudiar qué criticas les hacían los conservadores a los liberales radicales en el poder desde periódicos políticos, literarios y humorísticos como Los Locos, y cómo la caricatura política de Alberto Urdaneta se articuló con los debates en la prensa del momento. Es importante anotar que se hará una historia de las representaciones escritas y dibujadas, no necesariamente una historia de los hechos sino lo que se dijo sobre estos, cómo ciertos sectores de la sociedad colombiana representaron su entorno, sus opiniones y al "otro" político. El histórico conflicto político colombiano más allá de ser un enfrentamiento intelectual y racional también está marcado por una lucha pasional, en el cual al atacar al enemigo se ataca su identidad, su religión y sus perspectivas. $\mathrm{Hu}$ millados y ofendidos salían a la guerra; esta es una historia de la pugna ideológica colombiana que tiene tanto de intelecto como de pasión. Esto intuye que la prensa y la caricatura obtuvieron un papel singular en el escenario bélico del país, donde la guerra no solo era civil sino también editorial y de opinión.

\section{Abstract}

This article focuses on the analysis of the nineteenth century Colombian press, specifically, in the Estados Unidos de Colombia, 1863-1885. It is intended to study what criticisms the conservatives made of the radical liberals in power from political, literary and humorous newspapers such as Los Locos and how Alberto Urdaneta's political caricature is articulated with the debates in the press of the time. It is important to note that a history of the written and drawn representations will be made, not necessarily a history of the events but what was said about them, how certain sectors of Colombian society represented their environment, their opinions and the political "other". The historical Colombian political conflict, beyond being an intellectual and rational confrontation, is also marked by a passionate struggle, in which attacking a political enemy, their identity, their religion and their perspectives are attacked. Humiliated and offended they went to war; this is a story of the Colombian ideological struggle marked both by intellect and passion. This suggests that the press and the caricature had a unique role in the country's war scene, where the war was not only civil but also editorial and around opinion.

\footnotetext{
* Estudiante de Historia de la Universidad Nacional de Colombia, sede Medellín. Publicó en el volumen 6, número 12 de Quirón, revista de estudiantes de Historia una reseña sobre el libro ¿Realmente es necesario cortar la Historia en rebanadas?, de Jacques Le Goff. Correo electrónico: jsantos@unal.edu.co.
} 
Palabras clave: Estados Unidos de Colom- Keywords: Estados Unidos de Colombia; bia; prensa; caricatura; Alberto Urdaneta; si- press; caricature; Alberto Urdaneta; Colomglo XIX colombiano; Nicolás Pontón. bian nineteenth century; Nicolás Pontón

Para citar el artículo: Santos Gómez, Jacobo. "Humillados y ofendidos. Crítica conservadora al Olimpo Radical desde la prensa y la caricatura política de Alberto Urdaneta en los Estados Unidos de Colombia". Artificios, Revista Colombiana de Estudiantes de Historia, n. ${ }^{\circ} 19$ (2021): 36-64

Fecha de recepción: 26 de enero del 2021

Fecha de aceptación: 6 de mayo del 2021 


\section{Introducción}

Cuando hablamos de la prensa del siglo XIX en Colombia hay diferentes aristas que debemos tener en cuenta a la hora de analizarla. La sociedad colombiana en dicha temporalidad presentó características particulares que hacen de su estudio un tema más complejo de lo que se puede ver a simple vista. Las condiciones sociales, económicas, políticas y culturales desiguales eran prevalentes; no todos los ciudadanos podían leer, votar ni mucho menos poseer una imprenta y un periódico donde dar su opinión. Cuando hablamos de la prensa, de sus escritores, editores y directores se está acotando el grupo de estudio a una élite específica, hombres blancos y con cierta solvencia económica, probablemente casados. La opinión política y quien la leía y escribía no era un asunto necesariamente abierto a todo el público, pero esto no significa que no sea crucial y que su distribución y los debates que abrió sean menos importantes. Un espacio de sociabilidad de las élites para las élites; más allá de ser de un partido político o de otro, participar en la prensa era un privilegio político, económico y social. Simón Bolívar criticó a la sociedad colombiana en 1828, previendo esta desigualdad. Cuando la independencia fue obtenida la esperanza de cambio y de mejorar la sociedad estaba álgida, sin embargo, Bolívar se dio cuenta de que un cambio profundo iba a necesitar más que una independencia, anotaba que

[...] en Colombia hay una aristocracia de rango, de empleos y de riqueza, equivalente, por su influjo, por sus pretensiones y peso sobre el pueblo a la aristocracia de títulos y de nacimiento la más despótica de Europa. En aquella aristocracia entran también los clérigos, los frailes, los doctores o abogados, los militares y los ricos; pues aunque hablan de libertad y de garantías es para ellos solos que las quieren no para el pueblo que, según ellos, debe continuar bajo su opresión; quieren también la igualdad, para elevarse a los más caracterizados, pero no para nivelarse con los individuos de las clases inferiores de la sociedad: a éstos los quieren considerar siempre como sus siervos a pesar de todo su liberalismo'.

Sobre la prensa, Otero Muñoz afirma que perdió su antiguo carácter propagandista preindependentista para tornarse en una prensa de intereses locales, círculos cerrados y aislados, de fines electorales; esta fue la característica de la prensa en época federalista, un conflicto bipartidista que ahogó otras formas de periodismo ${ }^{2}$. Un ejemplo importante de esto es Nicolás Pontón, quien junto a su padre fue dueño de una imprenta en Bogotá donde se especializó en imprimir, editar y dirigir numerosos

1 Juan Luis Orrego Penagos, "Liberales y conservadores en el siglo XIX: un viejo debate", Historia Caribe 3, n. ${ }^{\circ} 8$ (2003): 69-70, https://www.redalyc.org/pdf/937/93700806.pdf.

2 Gustavo Otero Muñoz, Historia del periodismo en Colombia (Bogotá: Universidad Sergio Arboleda, 2019), 94, https://es.calameo.com/read/006431485ab8c4ce14268. 
periódicos de índole conservadora. Gozaba de cierta estabilidad económica que le permitía a él y a su familia dedicarse al oficio de la prensa. Pontón no era un artesano, se definía a sí mismo más como editor que como un impresor; fue uno de los diversos personajes que utilizaron la libertad de imprenta para plasmar sus ideales y objetivos en el papel ${ }^{3}$.

En este escenario social y político colombiano fue donde se desarrolló aún más la crítica, la sátira, el escrutinio mordaz y la fabricación de representaciones sobre el "otro", el enemigo político. La prensa y la caricatura van de la mano, ya que la primera genera las críticas y las opiniones sobre los personajes, y la segunda convierte esas opiniones sobre el enemigo político y las transforma en símbolos y arquetipos reconocibles, estereotipos e imaginarios sobre un sujeto ajeno el cual es satirizado y su imagen es exagerada para afianzar un punto político, religioso o moral. Se empezó a ver que las élites utilizaron la prensa para promover sus visiones políticas. Gracias a estos impresos los hombres de letras empezaron a moldear la opinión pública, la prensa de noticias e informativa se estaba diversificando, entró en auge la prensa de opinión, satírica, de humor y eventualmente la literaria ${ }^{4}$. Sin embargo, el lector se puede preguntar por qué escoger este periodo para analizar o por qué hubo un aumento en las publicaciones periódicas entre 1863 y 1885. Entre los cambios que sufrió el país durante todo el siglo XIX, los Estados Unidos de Colombia, también conocido bajo el rótulo de "Olimpo Radical", fue el periodo cuando los liberales mayormente radicales tomaron el poder y las riendas del país, y con ellos una nueva constitución se instauró repleta de las visiones, ideales y proyectos que esta rama del partido quiso proponer en el territorio.

\section{La tinta de la pluma: personajes, egos y el momento oportuno}

\section{"Quien quiera que se sublevase con éxito, podía pro- meterse convertir su violencia en autoridad".}

En una conferencia titulada "La historia de la historia de la caricatura en Colombia", en el marco del bicentenario de la independencia del país, un espectador le pregunta a Beatriz González por qué las caricaturas conservadoras fueron las más prominentes o las más conocidas del siglo XIX. A esto González respondió que fueron las que mejor

3 Fernando Murcia Sánchez, "Imprenta e institucionalización: la cultura letrada en las imprentas de José Antonio Cualla y Nicolás Pontón" (proyecto a la investigación en Historia Colonial, ICANH, 2013), 24, https://www.icanh.gov.co/nuestra_entidad/grupos_investigacion/grupo_historia_colonial_republicana/ resultados_proyectos_investigacion_6472/8428\&download=Y

4 Gabriel Samacá, "Prensa y divulgación de la historia patria en Colombia: la obra de Pedro María Ibáñez en publicaciones literarias e ilustradas, 1882-1919", Co-herencia 16, n. ${ }^{\circ} 31$ (2019): 323, https://doi. org/10.17230/co-herencia.16.31.10.

$5 \quad$ Otero, Historia del periodismo, 93. 
se conservaron a diferencia de las liberales, ya que muchas se perdieron y desaparecieron, y añade que la figura de Alberto Urdaneta fue tan importante y cargó tanto peso y renombre que giró el enfoque hacia su trabajo, además de que su papel como figura nacional lo cimentó como un marco de referencia cuando se habla de caricatura del siglo XIX ${ }^{6}$. Me gustaría añadir que el periodo entre 1863 y 1885 fue bastante singular, ya que la legislación y su estructura cambiaron radicalmente; la libertad de imprenta fue un derecho garantizado completamente en la Constitución de 1863, sin importar el partido político, la religión ni cualquier otro elemento identificador podían impedir la libertad de expresión. Cuando se lee dicha constitución en su artículo 15 que es donde tratan dicho tema de la libertad de imprenta, más específicamente en los apartados 6 y 7, se puede leer que no fueron escritos de una forma larga y con muchas condiciones:

Artículo 15.

6. La libertad absoluta de imprenta y de circulación de los impresos, así nacionales como extranjeros;

7. La libertad de expresar sus pensamientos de palabra o por escrito sin limitación alguna ${ }^{7}$.

Se puede ver que son dos frases bastante cortas que garantizan la libertad de imprenta y de impresos de manera nacional y absoluta, con libre circulación de escritos nacionales e internacionales, con libre expresión de pensamientos sin ningún tapujo. Es intencionalmente corta y sin condiciones para garantizar dicha libertad. El por qué se ve una gran cantidad de periódicos y de caricaturas políticas conservadoras entre 1863 y 1885 se debe en gran parte a que estos apartados permitían que los conservadores criticaran sin consecuencias ni censuras al partido "enemigo" que estaba en el poder. Se pueden ver casos de los conservadores denunciando el abuso de esta libertad, sin embargo, esta libertad de expresión fue algo que favoreció a los conservadores y a los liberales moderados para poder generar una crítica y una sátira de los radicales, que lentamente empezaron a perder el poder desde 1878. A diferencia de la Constitución de 1863, la constitución que la sucedió limitó fuertemente la libertad de prensa, de imprenta y de opinión. En vez de frases cortas y simples sin condiciones, se leen unas restricciones que la campaña de la Regeneración —impulsada por Rafael Núñez, un liberal moderado que se convirtió en conservador - impulsó desde 1878, pero que solo lograron implementar luego de la guerra civil de 1885-1886, ya que se escribió

6 Banrepcultural, "Beatriz González - La historia de la historia de la caricatura en Colombia (9/9)", video de YouTube, 15 de enero del 2010, https://www.youtube.com/watch?v=4WWbjZcWoqA\&ab_ channel=BanrepculturalBanrepcultural.

7 "Constitución Política 1 de 1863", Asamblea Nacional Constituyente, artículo 15, apartados 6 y 7 , https://www.funcionpublica.gov.co/eva/gestornormativo/norma.php?i=13698. 
una nueva constitución que permite comprender las quejas de los conservadores y de los liberales moderados. Esta nueva constitución dicta,

Artículo 42.- La prensa es libre en tiempo de paz; pero responsable, con arreglo a las leyes, cuando atente a la honra de las personas, al orden social o a la tranquilidad pública. Ninguna empresa editorial de periódicos podrá, sin permiso del Gobierno, recibir subvención de otros Gobiernos ni de compañías extranjeras.

Artículo K.- Mientras no se expida la ley de imprenta, el Gobierno queda facultado para prevenir y reprimir los abusos de la prensa $^{8}$.

Estos dos artículos remplazaron a los apartados 6 y 7 del artículo 15 de la Constitución de 1863. En estos dos artículos de la Constitución de 1886 se instaura la libertad de prensa y de imprenta con muchas más condiciones. En el artículo 42 se lee que la prensa es libre en tiempos de paz, "pero" se puede restringir cuando atente contra la honra, el orden social o la tranquilidad. Ese "pero" deja el debate sobre la libertad de expresión en aguas más turbias, ya que es bastante ambigua la causa en la que actúa. Proteger el buen nombre prohíbe las denuncias públicas contra hechos injustos, "atentar contra el orden social y la tranquilidad" abre un espacio legal en cual el gobierno conservador podría censurar y clausurar casas de imprenta y castigar escritores y editores que intentaran instigar y contradecir el nuevo orden conservador. Es por esto por lo que antes de la Constitución de 1886 se puede ver un gran volumen de periódicos, caricaturas y papeles sueltos de ambos partidos; más allá de su corriente política, se podía debatir y enfrentar al adversario de un periódico con otro periódico o con un artículo. El artículo K deja abierta la posibilidad, de forma explícita, de que el Gobierno puede, queda facultado y es legítimo para prevenir y reprimir los "abusos" de la prensa. La segunda parte del artículo 42 que dice "Ninguna empresa editorial de periódicos podrá, sin permiso del Gobierno, recibir subvención de otros Gobiernos ni de compañías extranjeras" cobrará sentido más adelante cuando se analice la crítica de los conservadores a los periódicos liberales y cuestionen de dónde obtenían su presupuesto para existir y publicar. Esa parte del artículo estuvo diseñada para prevenir la financiación de periódicos liberales con dineros que los conservadores consideraban injustos e incluso ilegales.

Las caricaturas en contra del Olimpo Radical gozaban de un espacio abierto para ser creadas y divulgadas durante el periodo 1863-1885. Crear una representación del presidente en turno, con símbolos que lo pueden hacer ver como un vampiro o como un jugador y adicto a la bebida eran posibles antes de 1886. Como señala Beatriz González, la palabra caricatura viene del italiano caricare, que traduce cargar, es decir, una imagen o un retrato cargado de símbolos, de humor y de sátira, escapando del mundo

8 “Constitución Política 1 de 1886”, Asamblea Nacional Constituyente, artículo 42 y artículo K, https:// www.funcionpublica.gov.co/eva/gestornormativo/norma.php? $\mathrm{i}=7153$. 
de la pintura se crea esta rama del arte que se enfoca en exagerar y en cargar un dibujo de elementos reconocibles para el espectador y generar una burla del representado ${ }^{9}$.

Esta modalidad del arte fue la especialidad de Alberto Urdaneta, que en el contexto del Olimpo Radical pudo generar una gran cantidad de caricaturas políticas en contra del régimen liberal radical. Realizó sus estudios en el Instituto de Cristo, en el Seminario de los Jesuitas y, finalmente, en la Academia de Mutis. En 1865, a la edad de 20 años, viajó a París, donde aprendió los métodos para la agricultura y la ganadería; de regreso al país, en 1868, se dio a la tarea de fundar El Agricultor, órgano informativo que le sirvió para iniciarse como periodista y en 1876 se vinculó activamente a la guerrilla de El Mochuelo, movimiento conformado por jóvenes conservadores que luchaban contra el gobierno radical de Aquileo Parra ${ }^{10}$. Desde una temprana edad tuvo los medios suficientes para viajar y estudiar en París, oportunidad muy escaza para la gran mayoría de los habitantes de Colombia, esto le permitió aprender varias técnicas y adquirir ciertos conocimientos que le dieron una ventaja a la hora de escribir y dibujar. Sus caricaturas reflejan una persona con unas creencias bastante católicas y conservadoras, elementos que no dudaba en incluir en su obra. Beatriz González señala que

Urdaneta se unió a la guerrilla, de la que formaban parte sus íntimos amigos, el 25 de agosto de 1876; a los diez días se encontraba preso en San Bartolomé. Esa fue la primera prisión del distinguido y adinerado joven bogotano. Al salir de la cárcel, ocho meses después, con motivo del armisticio, concibió con sus copartidarios un proyecto de acuerdo con su formación, que no traicionaba en nada sus ideales tradicionalistas: fundar un periódico de crítica verbal y gráfica ${ }^{11}$.

La vida y la obra de Urdaneta son consecuentes, su posición política era parte de su identidad, ya que no solo participaba de la crítica y la sátira hacia el Gobierno, sino que también a la edad de 31 años se unió a una guerrilla conservadora para pelear contra el gobierno de Aquileo Parra en la "guerra santa" o guerra de las escuelas. Debido a que los conservadores perdieron esta guerra, Urdaneta fue capturado y solo con el apoyo de su padre fue posible que lo dejaran en libertad, pero exiliado del país, en Francia. Cuando pudo volver de nuevo, en 1880, decidió crear una Escuela de Grabados, institución dependiente de la Universidad Nacional; también invitó al español Antonio Rodríguez, con quien planeó la ilustración de periódicos y más tarde crearían el Papel Periódico Ilustrado ${ }^{12}$.

9 Beatriz González, "La caricatura en Colombia a partir de la independencia", Banrepcultural, https:// www.banrepcultural.org/la-caricatura-en-colombia/texto01.html.

10 M. Ruiza, T. Fernández, y E. Tamaro, "Biografía de Alberto Urdaneta", Biografías y Vidas. La enciclopedia biográfica en línea, https://www.biografiasyvidas.com/biografia/u/urdaneta_alberto.htm.

11 González, "La caricatura en Colombia".

12 Ibid. 
Otro personaje relevante para esta historia, contemporáneo de Urdaneta, es Nicolás Pontón, ya mencionado, quien con su padre tenía la imprenta Pontón en su casa. Nicolás Pontón fue el editor e impresor del periódico satírico, humorístico y conservador Los Locos, junto con otras publicaciones. Fue una de las figuras más importantes en la prensa y en la difusión de la literatura colombiana del siglo XIX, además de ser un creyente firme de la libertad de prensa. Un momento crucial en su vida fue cuando sufrió un intento de asesinato por parte de un liberal:

[...] como por la tarde saliendo de su casa se le aparece aquel hombre y le pregunta si él es el redactor de un periódico llamado La Bruja. Nicolás Pontón le responde que él es el editor y no el redactor. Insatisfecho con la respuesta Rivas exclama "Si U. no me dice ahora mismo quien es el Redactor, lo mato". El suceso tiene que ver con el deseo de hacer justicia ante lo dicho en una publicación que enfrentó a liberales y conservadores. Pontón no le da el nombre del editor a su posible asesino, dice con sus palabras "yo no tengo que dar a U. ningún nombre porque hay libertad de imprenta". Después de esto sigue una escena en la cual Rivas saca un puñal e intenta clavarle tres puñaladas a Pontón, pero no lo consigue. Entonces, "a ese tiempo los oficiales de la imprenta, habían gritado a mi padre diciéndole que me estaban asesinando", comenta Pontón, y acto seguido el padre lo defiende también con un puñal; el altercado no deja ningún muerto, solo a Rivas levemente herido y a Pontón, envalentonado por la osadía de este liberal que lo había esperado afuera de su casa para matarlo por una publicación impresa en su imprenta. A partir de allí en más, se publica cierta cantidad de hojas por el estilo que tienen como fin negar la responsabilidad del impresor sobre cualquier cosa publicada en su imprenta, apelando a la legalidad presente que dictaminaba la completa libertad de impresión ${ }^{13}$.

Este suceso no solo demuestra la violencia bipartidista que vivía el país en el siglo XIX, cuando era una fibra sensible hablar o enfrentar a dos personajes de partidos diferentes, sino que muestra una posible explicación de la posición ultraconservadora que Pontón asumió en su vida y que hechos como este pudieron haber incentivado y profundizado. Al analizar la vida de Pontón se puede ver su pasión por su trabajo como editor y/o director de periódicos, también como escritor de algunos otros trabajos; aunque la imprenta era un trabajo familiar, su vocación estaba en las letras. Además de editar e imprimir Los Locos, Pontón escribió un relato titulado "Nuestro siglo XIX" en 1868; dos obras de teatro en 1872 tituladas "Tres diablos sueltos: juguete escénico" y "Una idea-abismo"; y otros textos como "Ecos de noche" de 1870 y "El arte de probar el alcance de todo el mundo"14.

13 Murcia, "Imprenta e institucionalización”, 22.

14 Flor María Rodríguez-Arenas, Bibliografía de la Literatura Colombiana del siglo XIX, Tomo 2 M-Z (Bogotá: Stock-cero, 2006), 3-5, https:/www.stockcero.com/pdfs/978-987-1136-47-6_SAMP.pdf. 
También Cacua Prada en su Historia del periodismo colombiano hace una compilación de los periódicos en los que participó, editó o dirigió Pontón, como El Bogotano en 1863, en el que mostró una vez más su tinte político diciendo: "Señores conservadores. Mi propósito es bien claro: Entrad par diez! por el arco haciéndoos suscriptores" ${ }^{\prime 15}$. Pontón después editó el Semanario de Avisos, y mostró el gran papel de su creencia religiosa al dirigir La Voz del Catolicismo en $1864^{16}$. El Museo literario y El Rocio surgieron en 1871 y culminaron en 1871 y 1875 , respectivamente. Cacua menciona que Pontón era un publicista incansable y un decidido propagador de la literatura y prensa nacional. Pontón comenzó La ilustración, en la que tomó el puesto de director en 1880, y ese mismo año creó dos periódicos literarios llamados La Pluma y La Velada ${ }^{17}$.

Este gran acervo de publicaciones creadas o editadas/dirigidas por Pontón muestran su rol incansable por la difusión no solo de sus ideales políticos y religiosos, sino que al parecer al final de su vida optó por centrarse más en periódicos y publicaciones literarias y cada vez menos en publicaciones políticas y de opinión, tal vez porque el Olimpo Radical ya estaba en decadencia para la década de 1880 o por un hastío general de las publicaciones políticas y se enfocó en el renacimiento de la literatura colombiana que se vivió desde las últimas dos décadas del siglo XIX, como sugiere una cita de La Pluma en la que Pontón, como su editor, anuncia que

[...] este periódico se consagra exclusivamente a la literatura patria. En servicio de ella, publicará, complacido y hasta orgulloso, las producciones de la juventud colombiana, tan ricamente inspirada; y reproducirá, de las bellas letras extranjeras, cuanto pueda servir de modelo. La esterilizadora política le será extraña en absoluto; sirvan de prenda para ello, los conocidos nombres del editor y los redactores, cuyas opiniones, desacordes, en asuntos de aquella naturaleza, - aunque profundas y sinceras para cada uno- sostendrán, por mutuo contrapeso, el fiel de la abstención ${ }^{18}$.

Asimismo, el gran número de publicaciones y periódicos se debía a que muchos no duraban. Si usamos el caso de Pontón de ejemplo, muchos de sus periódicos se mantenían en producción durante uno o dos años en promedio, siendo cinco años el que más duró. Muchos factores influenciaban la corta vida de los periódicos y la

15 Antonio Cacua Prada. Historia del periodismo colombiano (Bogotá: Fundación El Libro Total, 1968), 345-346, https://www.ellibrototal.com/ltotal/?t=1\&d=7826.

16 Ibid., 348-373.

17 Ibid., 373-468.

18 Olga Vallejo Murcia, Ana María Agudelo Ochoa y Xiomara Meneses Cano, "Publicaciones seriadas de la literatura colombiana. Fuentes periódicas para el estudio histórico de la literatura colombiana. Compilación y reseña. Primera entrega", Estudios de Literatura Colombiana, n. ${ }^{\circ} 28$ (2011): 174, https:// dialnet.unirioja.es/descarga/articulo/3876295.pdf. 
prensa tomó una velocidad sin precedentes en los Estados Unidos de Colombia ${ }^{19}$. Sin embargo, una vez conocidos los perfiles e historias de dos de los autores más relevantes en este estudio, es hora de analizar qué se decía en las páginas de los periódicos y cómo se satirizaba a los personajes en las caricaturas de Urdaneta. La prensa en el siglo XIX se convirtió en un campo de batalla ideológico, político, religioso, económico y cultural, con un gran peso en la sociedad colombiana y con consecuencias tan reales como el atentado contra Pontón o el poder de difundir noticias, ideas y opiniones que le llegaban a una parte reducida de la sociedad; sin embargo, la élite colombiana masculina y blanca era quien tomaba las decisiones y/o quien votaba.

\section{El filo de la hoja}

"La imprenta, durante esta época y en lo que respecta a las publicaciones periódicas, se usa como caballo de guerra en el que se mandan a la batalla textual a los periódicos, buscando algún tipo de victoria simbólica y literaria sobre los destinatarios "20.

El papel del caricaturista es multifacético, ya que no es solo necesario que sepa dibujar, sino que es vital que entienda y represente los símbolos necesarios para trasmitir un mensaje y una opinión específica. Dos habilidades y destrezas que debían incorporar era la del humorista y dibujante, mezclando elementos preiconográficos como adornos, armas, emblemas, palabras, signos, señales que articulaban y dejaban ver el bagaje, influencias, experiencias, intereses y sus fines, así como el contexto en el que se encontraban y el ambiente reinante ${ }^{21}$. Es decir, toda la subjetividad del ser humano aplica también para el caricaturista y sus obras, no es una pieza inocente y objetiva que refleja la realidad o los hechos, sino que parte de la realidad y la reinterpreta fuertemente, para que coincida, en la mayoría de los casos, con su visión del mundo, sus tendencias políticas, morales y religiosas, entre otras. Es por esto por lo que la caricatura es una fuente privilegiada para analizar y acercarse al pasado y entender las opiniones, representaciones e influencias de los personajes estudiados. Un gran debate que se puede leer cuando uno confronta autores que trabajan la caricatura política de forma histórica, como Darío Acevedo y Beatriz González, es si la historia de la caricatura es la historia patria y la historia de Colombia, a lo que me gustaría añadir que sí, es estudiar una visión particular y subjetiva, pero que revela y da grandes pistas para analizar la gran imagen del siglo XIX colombiano. Los sujetos hacen y participan de

$19 \quad$ Ibid., $160-161$.

20 Murcia, "Imprenta e institucionalización", 23.

21 Darío Acevedo Carmona, "La caricatura política y la violencia liberal-conservadora", Credencial Historia, ${ }^{\circ}{ }^{\circ} 125$, https://www.banrepcultural.org/biblioteca-virtual/credencial-historia/numero-125/lacaricatura-politica-y-la-violencia-liberal-conservadora. 
la historia, y analizar su condición de entes subjetivos es estudiar la historia y quienes la componen.

En un artículo donde se analiza la caricatura de 1940, Darío Acevedo señala algo que se puede aplicar también a la hora de acercarse a las caricaturas de los Estados Unidos de Colombia. Aunque un contexto bipartidista como el de 1940 no se asemeja completamente al de la segunda mitad del siglo XIX, Acevedo subraya que

Resume la política editorial del periódico y el pensamiento del partido o facción partidista con el que se identificaba. Los caricaturistas eran reiterativos y recurrentes en el uso de algunas simbolizaciones, en apoyarse en ciertos estereotipos y en acometer contra determinados personajes, casi hasta la obsesión, causando la impresión de estar haciendo un producto meramente propagandístico. Ernst Cassirer en El mito del Estado nos da la clave para comprender mejor este asunto, cuando explica que en las sociedades modernas la lucha por el poder ha involucrado técnicas de propaganda masiva a través de las cuales se orienta y se manipula a la opinión pública. La caricatura de entonces, sin duda, cumplía funciones de propaganda política al irradiar la opinión pública con sus representaciones, sus conceptos e ideas moldeadas en imágenes metafóricas o analógicas ${ }^{22}$.

Es entonces importante aclarar que la prensa y las caricaturas entran en esa categoría (o deseo) por convencer al espectador, hacer que apoyase ciertas ideas políticas y de presentar un claro enemigo político el cual es reconocible por los estereotipos y arquetipos creados sobre él a través de símbolos y signos identificables por el contexto en el que se encuentre inmerso el espectador. En los Estados Unidos de Colombia se vieron a unos liberales radicales creando leyes y restructurando el aparato judicial y constitucional por uno que se alineara con sus propuestas e intereses. Esto generó un anhelo conservador por retomar el poder a como diera lugar e implantar su propia visión del país y sus habitantes. La prensa y la caricatura fueron unas de las herramientas para hacer eso. Ambos partidos y personajes disidentes utilizaron las mismas herramientas y otras más para afianzar sus campañas, lo que no significa que sea algo negativo per se, sin embargo, es importante reconocer estos patrones y técnicas, pero no creer inocentemente que el humor y la sátira pertenecen al terreno del desinterés. Basilien-Gainche afirma que desde el inicio del siglo XIX se vieron distintos grupos políticos como los realistas e independentistas, bolivarianos y santanderistas, conservadores y liberales que se disputaron el control de la gobernanza del país, pero que los liberales y conservadores tenían una disputa que giraba en torno al control del aparato constitucional, y que esto se lograba por la fuerza, en las guerras civiles, el control de las tierras y los caudillos y comandantes de hombres ${ }^{23}$. Yo agregaría que también es

$22 \quad$ Ibid.

23 Marie-Laure Basilien-Gainche. "La constitucionalidad de contienda: la promoción jurídica de la guerra 
crucial contar con la opinión pública, con el favor del pueblo, de los habitantes y con sus votos, todo esto es posible en parte a lo que leen, a las noticias, las opiniones y las representaciones que se construyen de cada uno de los líderes de cada partido político.

Uno de los líderes más importantes del siglo XIX fue Tomás Cipriano de Mosquera, parte de la élite del Cauca y presidente de la nación en cuatro ocasiones: presidente de La República de Nueva Granada entre 1845 y 1849; presidente de la Confederación Granadina entre 1861 y 1863; y de los Estados Unidos de Colombia entre 1862 y 1864, y de 1866 a 1867. Mosquera ha sido uno de los personajes más representados, criticados y satirizados por la prensa conservadora por muchos motivos, especialmente porque en su primera presidencia hacía parte del Partido Conservador, pero luego se cambió de partido y lideró la corriente liberal radical que instauró la Constitución de 1863. En la prensa conservadora se le representaba como un dictador por la cantidad de veces que fue presidente, por su peso en la política colombiana y por impulsar varias leyes que los conservadores condenaron como injustas y profanas. En el primer número de Los Locos se puede ver que el objetivo del periódico se estaba trazando con su primera publicación y que Mosquera era un referente crucial para ser criticado:

Si, señores, aquí no hai mas que el antagonismo de los clásicos con los románticos i los eclécticos; conservadores, gólgotas i liberales; pero hai que advertir que no debemos atenernos a los nombres, especialmente al de los últimos; los liberales colombianos tienen de todo, menos liberalismo. Yo no sé cómo se pueda ser liberal i dictatorial o mosquerista a un mismo tiempo; a mí no me la meten; así como tampoco concibo cómo se pueda ser buen conservador y masón; pues entiendo que el conservatismo se apoya en el catolicismo i mui pocos masones veo yo en misa. Pero esto no es tan estraño; mas raro es que hai conservadores solo van a la iglesia a algún entierro; i hai liberales mui calificados i probados, i hasta de los conquistadores de manos muertas, que por nada se quedan sin su misa, por lo menos los días de fiesta. Anomalias, contrasentidos ${ }^{24} \ldots$

Se criticó a los liberales por llevar su nombre de forma nominal al apoyar a un "dictador" como Mosquera, se subrayó la profunda contradicción de ese partido e implícitamente se acusó de hipocresía a quienes hicieran parte de un grupo político y no cumplieran con las "características" esperadas o alabadas por los conservadores. Por ejemplo, los liberales son nominales si apoyan a Mosquera por ir en contra de la libertad apoyando al "tirano", los conservadores deben ser católicos y no pueden pertenecer a la masonería. "Anomalías, contrasentidos...". También se señala que "Los

civil en la Colombia del siglo XIX", Historia Crítica, n. ${ }^{\circ} 35$ (2008): 148.

24 "Primera Perorata de prejuicios", Los Locos, 18 de marzo de 1868, 2-3, http://babel.banrepcultural.org/ digital/collection/p17054coll26/id/1905. 
conservadores casi no son un partido político; mas bien parece un partido eclesiástico. Por eso la llevan perdida en sus encuentros con los liberales. Aquellos apelan al espiritualismo; estos al materialismo i triunfan materialmente" ${ }^{25}$. Este último fragmento deja ver la impotencia conservadora al no poder ganar unas elecciones en 1868, año en el que fue escrito este artículo; se les achaca la culpa a las diferencias en creencias, ya que los conservadores son más espirituales y se definen a sí mismos como religiosos católicos, mientras que los liberales apuntan a metas materialistas con las que triunfan. En el periódico Los Locos, que era especialmente conservador, humorístico y satírico, algunas veces se podían encontrar rasgos de un periódico literario, revelando las inclinaciones tempranas de Pontón por la literatura. En Los Locos se plasmaban de vez en cuando algunos poemas de índole político que desde la prosa hacían una crítica a su entorno, al Gobierno y a los líderes en el poder ${ }^{26}$ :

[...] Así clamamos hoi dia

Los buenos contra los rojos.

[...] Es decir, no el del pezcueso

Sino el coto de la mano,

Con que miden grano a grano,

Los que vinieron por eso:

De su avaricia el exceso

No les deja reparar, Que si hoy pueden medrar

A la sombra de Mosquera

Cuando el miserable muera

Se las puede recordar.

[...] I aun hubo conservadore
(Que en todas partes hai Júdas)

Que pusieron mil dudas

En favor de los traidores.

Mas los buenos servidores

De la bandera vencida,

Vieron la patria perdida

En tan miserables manos,

Que no son estos villanos

Hombres para tal partida.

[...] Mas no echaron en su cuenta

El carácter soberano

Del ridículo tirano $[\ldots]$

Este poema toma diferentes signos y símbolos para trasmitirle al lector un mensaje bastante contundente. Cuando dice "Así clamamos hoy día los buenos contra los rojos", se está refiriendo a los colores de cada partido, los azules son los conservadores - o como se autodenominan, "los buenos"-, contra los rojos, que es el color insignia del Partido Liberal. No solo se están definiendo por colores, sino que también se le está haciendo un juicio moral y de valor a los que portan un color específico. "Los buenos" católicos contra los rojos, que no poseen un adjetivo que los salve, así que se asume que son "los malos". Se rotula a los "rojos" como avaros, que cuentan cada grano, que aún se mantienen a la sombra de Mosquera, pero que cuando este muera se les va a recordar lo sucedido. No solo se representa a Tomás Cipriano de Mosquera como un ente arrollador y que dirige a sus partidarios, sino que al mismo tiempo se

25 Ibid., 3.

26 "Los Dos Altos Poderes Nacionales en 1867. Historia", Los Locos, 29 de abril de 1868, 1, http://babel.banrepcultural.org/cdm/compoundobject/collection/p17054coll26/id/2096/rec/1. 
les quita la autonomía y la voz a sus seguidores, que como ciegos lo siguen sin importar lo que haga. Este poema permite leer una polarización latente en ese contexto, ya que cualquier conservador que apoyara a Mosquera y a los liberales era automáticamente un traidor, y, además, se vilifica a Mosquera, que es nombrado literalmente un "villano" y un "ridículo tirano". Se empiezan a ver señales de una deshumanización del otro, donde Mosquera ya no es un líder o un presidente, sino que es un enemigo sumamente malvado, un "tirano" ridículo que actúa como un villano despótico. Este tipo de adjetivos utilizados para referirse a un sujeto se convierten en sustantivos para referirse al personaje aludido, palabras como "ridículo", "villanesco", "tiránico", "traidor" adoptan un sujeto (él) y una característica para definirlo, y se convierte en "el ridículo tirano", "el traidor", "el villano". Este tipo de esencialismos son los que alimentan a la caricatura, que toma prestadas dichas palabras, símbolos y signos para construir una representación gráfica del personaje vilificado; ya no es una persona del común, es un enemigo con cierta historia, ciertas características y ciertos términos para referirse a él directamente.

Una crítica similar hacia Mosquera y los "mosqueristas" se puede encontrar en una carta publicada como artículo en el décimo número de Los Locos, donde se escribe: "cuando ya creíamos que la división era eterna i que seguiríamos dislocados, los unos adorando al sancarron, i los otros cerrados a no permitir que el gran caudillo volviese nunca a protegernos con su buen gobierno"27. Se muestra un gran alivio porque el Zancarrón, que sería Mosquera, no ganó las elecciones con el candidato de su partido, Eustorgio Salgar; se le menciona de forma sarcástica como un "caudillo" y continúa la burla diciendo que ya no podrá "protegernos con su buen gobierno".

Más adelante el autor de la carta continúa señalando las divisiones dentro del Partido Liberal, sus distintos matices y las alianzas que debieron hacer para mantener el poder, pero que no significa que los mosqueristas y los gólgotas sean lo mismo: "No crea usted, compadre, en que esas uniones son verdaderas: los gólgotas i mosqueristas nunca podrán quererse; vivirán siempre como mal matrimonio, que un dia se comen a cariños i al siguiente hai divorcio [...]. Los gólgotas no pueden amañarse con los secuaces de la dictadura $[\ldots]^{\prime 28}$. Este fragmento señala que, según este escritor conservador, los gólgotas también eran conscientes del culto a la personalidad que mantenía un sector liberal hacia Mosquera, mostrando unos matices que separan a distintos grupos que, bajo el mismo rótulo de liberales, son quienes disiden en grandes puntos de sus agendas particulares. Sin embargo, el autor hace hincapié en la compleja relación entre liberales mosqueristas y liberales gólgotas: los une en su odio a la religión, cosa que los separa fuertemente del conservatismo colombiano, que tiene unas fuertes raíces católicas y que considera una fuerte ofensa cualquier ataque a la Iglesia: “[...]

27 Pedro Pérez, “Carta”, Los Locos, 9 de mayo de 1868, 1, http://babel.banrepcultural.org/digital/collection/ p17054coll26/id/1912.

Ibid. 
Verdad es que, en ciertos puntos, unos i otros están siempre de acuerdo; como en esto de las creencias, o mas claro, el catolicismo. Cuáles de ellos desprecian mas la relijion, eso no lo sabemos; pero que todos, gólgotas i mosqueristas, la desprecian, eso es un hecho ${ }^{29}$

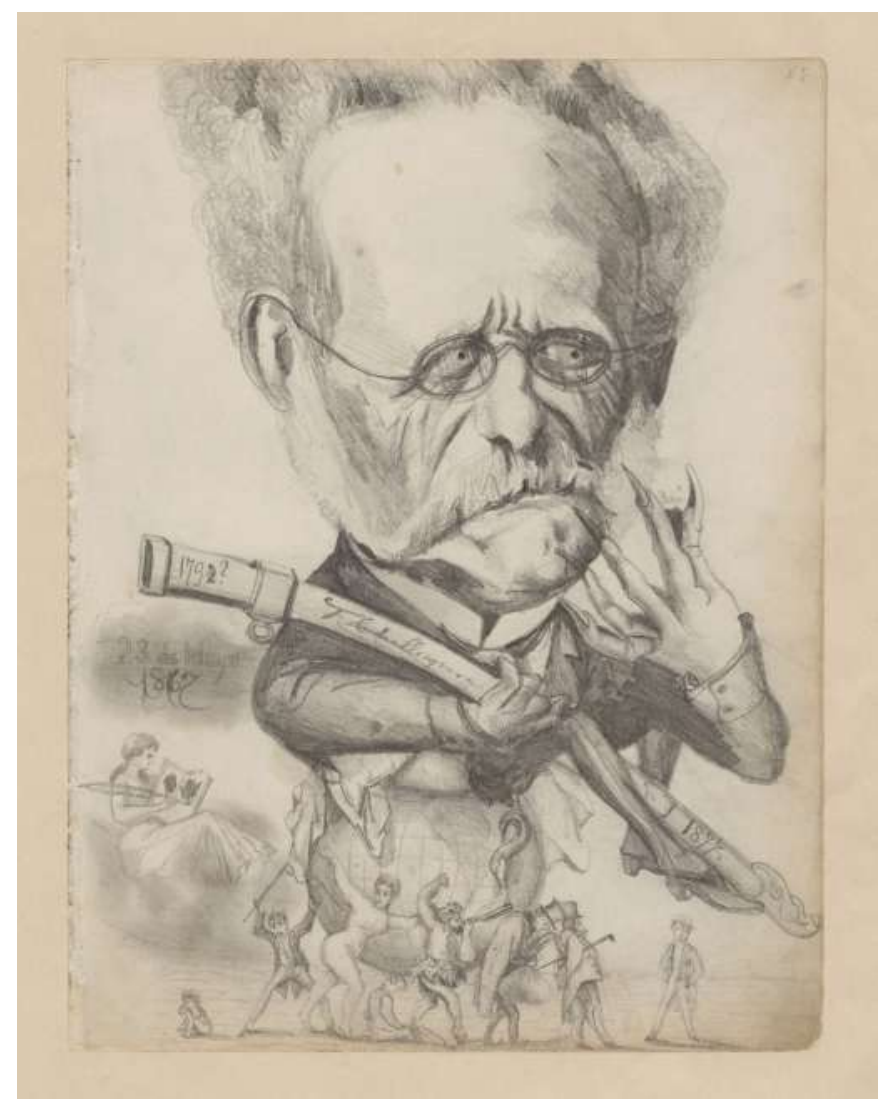

Figura 1. "Tomás Cipriano de Mosquera: 1792?-1877”.

Fuente: Alberto Urdaneta, “Tomás Cipriano de Mosquera: 1792?1877”, (Bogotá, 1877), Biblioteca Nacional de Colombia (BNC).

En la Figura 1 se puede ver una caricatura hecha por Urdaneta en 1877 durante los meses que pasó en prisión tras ser capturado al finalizar la "guerra santa", esta representación fue tomada de su cuaderno de dibujos titulado "Ecos de mi segunda prisión". En él, dibuja a un Tomás Cipriano de Mosquera de una edad avanzada, con un rostro demacrado y los ojos con una mirada sombría, ya que Urdaneta le trazó con el lápiz una sombra sobre los ojos; sus manos tienen las uñas largas y su aspecto en general parece el de un villano "vampiresco"; tiene una espada de gran tamaño que dice "1792?" y al otro extremo escribe 1877 , posiblemente significando el gran periodo que ha vivido Mosquera, aunque este nació en 1798 y no en 1792, tal vez por eso incluyó el signo de pregunta. Mosquera fue representado sentado sobre el globo terrá- 
queo, mientras que varias personas, entre ellas una mujer, un sátiro y varios hombres vestidos elegantemente levantan el mundo sobre el que Mosquera se sienta.

Esta representación que Urdaneta hizo en 1877 encaja con varios de los puntos tratados hasta el momento. El gran tamaño de la cabeza y del cuerpo de Mosquera, al igual que su apariencia macabra entran en las descripciones como "villano" y un "traidor". Al mismo tiempo que su acción de sentarse sobre el mundo por muchos años, desde "1792?" hasta "1877", mientras que la gente que le levanta el mundo se cansa. Es una crítica bastante ágil de la percepción de Mosquera como un “dictador” y un "tirano", y refleja una sátira al egocentrismo que Urdaneta percibió en Mosquera como un "dueño del mundo", cuando en realidad es cargado por la gente. Su gran tamaño también puede ser una alusión al carácter de Mosquera opacando la política colombiana y a los miembros de su mismo partido. La capacidad de Urdaneta de condensar en un solo dibujo diversas referencias, símbolos y signos que aluden a un debate mucho más grande demuestra que el caricaturista estaba consciente y conocía lo que se decía de Mosquera, y sus inclinaciones políticas conservadoras lo llevaron a representar al político de una forma satírica y humorística, siempre mofando y criticando al representado al mismo tiempo.

Durante el Olimpo Radical es común encontrar diversos artículos de periódicos y hojas sueltas conservadoras preguntándose el porqué de su derrota electoral cada dos años hasta 1878. La crítica y la sátira no se detenían solamente con Mosquera, los conservadores representaban y discutían también diferentes líderes liberales radicales y moderados que a su parecer poseían cualidades antipatrióticas e, incluso, que perjudicaban a la nación, a Dios y la economía. En el número undécimo de Los Locos se habla de esta duda, ¿por qué están ganando los liberales?, ¿qué están haciendo los "rojos" para ganar y qué no están haciendo los conservadores para triunfar?:

Alguno de ellos dirá: "Pero si cada estudiante votó tres o cuatro veces; i los rojos echaban de a dos o más boletas “... Nosotros respondemos: pues por lo mismo debimos ir todos a votar, para equilibrar las trampas. Los Liberales, como ellos se llaman, no pueden ganar aquí elecciones sin cometer fraudes; es cierto; pero si todos los electores conservadores votaran, aunque se despezuñaran aquellos, no las ganarían ${ }^{30}$.

La respuesta que ese artículo sugiere es: 1) los conservadores no salen a votar y esto permite una victoria liberal; y 2) los "rojos" hacen trampa y fraude electoral para ganar las elecciones, votan varias veces, y se tipifica a los estudiantes como uno de los sujetos que propician estas trampas. En el mismo número de Los Locos se encuentran varios anuncios y artículos que invitan a su audiencia a votar, ya que es incomprensible la derrota electoral que sucedía en el Olimpo Radical. En este periodo los conser-

30 Nicolás Pontón, "Cúlpense a sí mismos", Los Locos, 18 de junio de 1868, 1-2, http://babel.banrepcultural.org/digital/collection/p17054coll26/id/1903. 
vadores cuestionaron cualquier empresa o institución liberal, ¿de dónde obtenían su dinero?, ¿cómo podían mantenerse a flote?, ¿quiénes los apoyaban?:

¿Cómo se sostienen los periódicos liberales en Bogotá? Por medio de las suscriciones de los señores conservadores. Anomalías! I ningun liberal se suscribe a los periódicos conservadores; si se suscribieran, seria partido igual. Resulta, pues, que los conservadores dan su dinero a quien los deprime i maltrata. Serian capaces, algunos por lo menos, de dar el cuartillo para el lazo con que habían de ahorcarlos. Pero lo mas inesplicable es que esos señores conservadores que sostienen los peródicos liberales, esquivan el suscribirse a los periódicos de su partido. ¡Viceversas i semiversas de nuestras jentes! ${ }^{31}$.

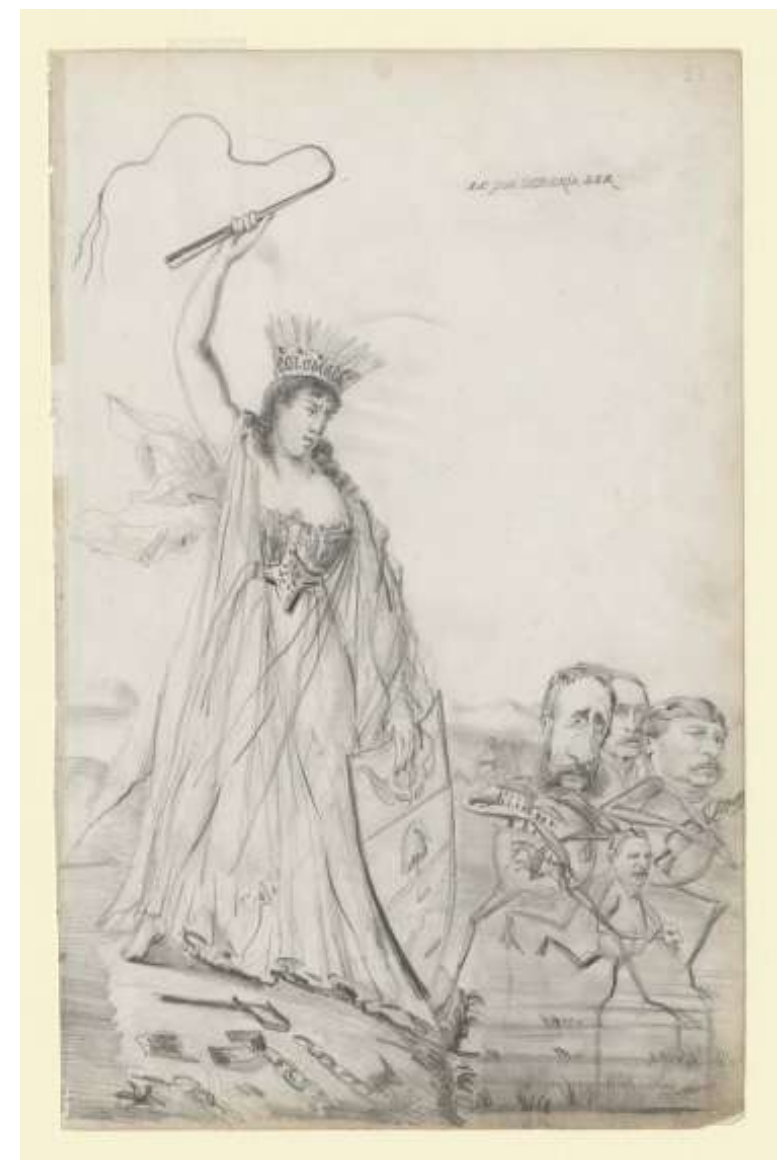

Figura 2. "Lo que debería ser".

Fuente: Alberto Urdaneta, "Lo que debería ser”, (Bogotá, entre 1863-1885), BNC.

La duda sobre las empresas, los periódicos e instituciones liberales fue constante durante el Olimpo Radical; los conservadores no lograban razonar cómo pudieron

31 “Otra pregunta", Los Locos, 18 de junio de 1868, 2, http://babel.banrepcultural.org/digital/collection/ p17054coll26/id/1903 
ganar tantas veces. Sus explicaciones giraban en torno a fraudes electorales y económicos, inversiones extrajeras que a sus ojos eran ilícitas o a que los conservadores apoyaban la campaña liberal directamente como traidores o indirectamente al no votar. Este prejuicio de asociar a los "rojos" con el fraude y la trampa o, incluso, con la corrupción, se cristalizó al representar a diversos líderes liberales como sapos, de ahí el origen del "sapismo"32.

La Figura 2 representa una escena de una mujer alta con una corona que inscribe "Colombia", con el escudo de la nación en una mano y batiendo un látigo con la otra. Esto nos permite decir que sería una alegoría para la nación o la madre patria y persigue a cuatro hombres que huyen despavoridos de su ira; los hombres en cuestión tienen cuerpo de sapo y cara de humano, en sus brazos sostienen pertenencias como ganado, propiedades, estatuas; y un sapito en particular lleva una máscara en sus manos. Al fondo, sin mucho detalle, se pueden ver esbozados más sapos que no poseen detalles característicos. Los cuatro personajes reconocibles son Jacobo Sánchez, gobernador de Cundinamarca en 1876; Manuel Murillo Toro, dos veces presidente de la nación en 1864-1866 y 1872-1874; Ramón Gómez, senador de la república y por quien surgió el término "sapismo"33; y el doctor Nicolás Esguerra, abogado y político liberal. Todos ellos pertenecieron al Partido Liberal colombiano y fueron tildados de sapos por los conservadores, que los asociaron a la corrupción y al fraude. Esta caricatura muestra a Colombia, representada por la madre patria, echando a los sapos; estos huyen agarrando cualquier bien que puedan, en su situación lamentable y avara mientras escapan de una Colombia que "despertó" y ya no va a soportar el robo y la corrupción de los liberales. Representar humanos como animales tiene un significado bastante específico, según Jurado

Resulta pues, que las relaciones entre los animales también se presentan en ciertas relaciones objetivas o imaginarias con los hombres, y son inherentes al trato y a la convivencia social que rige en una sociedad durante una época determinada. Las metáforas y simbolismos zoológicos a los que se acudía para señalar conductas o características de un grupo social hacían parte de las formas de diferenciación social de las relaciones de poder y de los valores sociales vigentes en la Antioquia de los siglos XVIII y XIX ${ }^{34}$.

Darles simbolismos zoológicos a ciertos personajes se utilizaba para señalar conductas morales de un grupo social ajeno al nuestro, en un intento por generar una diferenciación social, moral y política. Al representar a los liberales como sa-

32 González, "La caricatura en Colombia".

33 Ibid.

34 Juan Carlos Jurado, "La zoociedad antioqueña en los siglos XVIII y XIX”, Credencial Historia, n.

97, https://www.banrepcultural.org/biblioteca-virtual/credencial-historia/numero-97/la-zoociedadantioquena-en-los-siglos-xviii-y-xix. 
pos se envió el mensaje de que en conjunto eran corruptos, fraudulentos y que esas características no eran compatibles con la madre patria, quien despertó para echarlos o extraditarlos del país, práctica común aplicada a los enemigos políticos más notables de cualquier partido. Con las representaciones caricaturescas y satíricas como la del villano, el traidor, el dictador o los sapos se trazó una línea de división de "nosotros" y el "enemigo", que ya estaba delimitada con ciertos valores morales, adjetivos, sustantivos y características que lo deshumanizaban y lo subrayaban como un personaje que tocaba extraditarlo y era crucial cambiar su constitución por mi constitución.

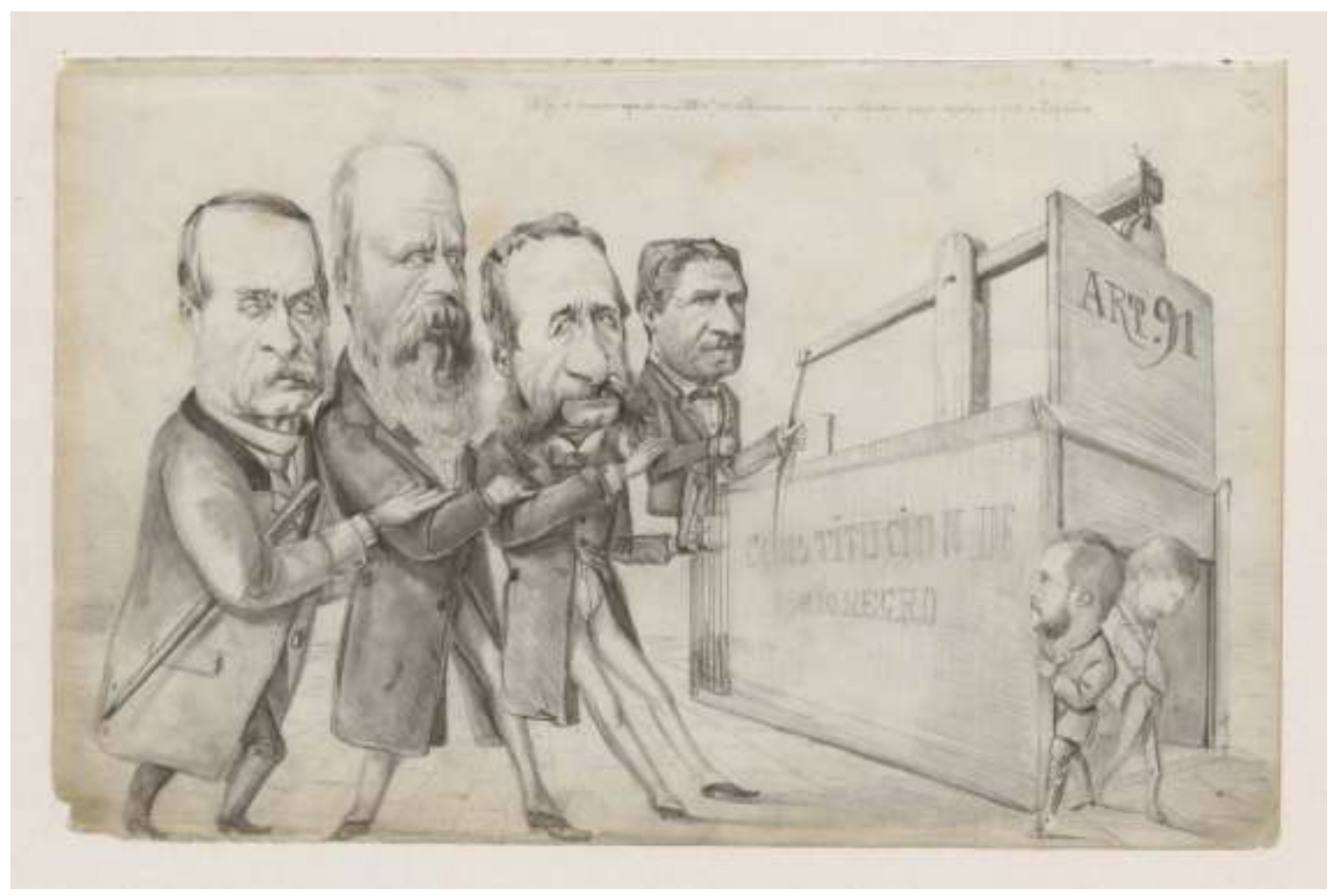

Figura 3. "Constitución de Rionegro: art 91".

Fuente: Alberto Urdaneta, “Constitución de Rionegro”, (Bogotá, 1876), BNC.

La Constitución de 1863 fue uno de los ejes centrales de la crítica conservadora hacia 1877. En la Figura 3 Urdaneta dibujó a Aquileo Parra, presidente de Colombia desde 1876 hasta 1878; a Jacobo Sánchez, ya mencionado gobernador de Cundinamarca; a Manuel Murillo Toro, expresidente de la nación; y a Nicolás Esguerra, político y abogado liberal, utilizando la Constitución del 63 como una trampa para cazar conejos y el artículo 91, que dictaba

el derecho de gentes hace parte de la legislación nacional. Sus disposiciones regirán especialmente en los casos de guerra civil. En consecuencia, puede ponerse término 
a ésta por medio de tratados entre los beligerantes, quienes deberán respetar las prácticas humanitarias de las naciones cristianas y civilizadas ${ }^{35}$.

La puerta de la trampa es dicho artículo y parece que va a atrapar a dos personas que no se han dado cuenta de la situación en la que se encuentran. Esta caricatura no solo critica a los personajes ya mencionados, sino que es una crítica directa a la Constitución de 1863 y al artículo 91. En El Comercio, periódico conservador y noticioso dirigido por Rufino Gutiérrez Isaza, político y militar conservador director de la imprenta Zalamea hermanos y socio de la imprenta Gutiérrez Hermanos ${ }^{36}$, se señala que

En aquel tiempo, como habría dicho el Evangelista, bastaba la ojeriza de un alto empleado, alto por la colocación, bajo por el procedimiento, para que de la noche a la mañana se rompieran puertas, se saquearan almacenes; todo eso sí en nombre de la libertad individual y de todas las libertades consagradas en el papel por los convencionistas de $63^{37}$.

Gutiérrez menciona sarcásticamente las libertades individuales consagradas en la Constitución de 1863; habla de crímenes cometidos como saqueos y vandalismo, y se los achaca al "libertinaje" que dicha constitución, según fuentes conservadoras, permitió. Después de Aquileo Parra, el último liberal radical en ser presidente de la república, en 1878 empezaron a ganar las elecciones los liberales moderados, quienes con el apoyo de los conservadores iniciaron la Regeneración, dando fin a la hegemonía radical. Sin embargo, fuentes como Rufino Gutiérrez permiten leer que aunque los radicales ya no estaban en el poder su constitución seguía vigente y sus leyes seguían afectando el curso del país. Es por esto que la guerra de 1885-1886 fue principalmente para reescribir una nueva constitución. La lucha por el control del aparato institucional nunca había cesado desde 1863; la idea de cambiar la constitución estuvo en el imaginario conservador desde que a la Constitución de Rionegro se le estaba secando la tinta. Incluso una gran parte del Partido Liberal se adhirió a los ideales de la Regeneración, que buscaban aplacar las tensiones bipartidistas. De hecho, fue el presidente liberal Santos Gutiérrez quien acuñó el término Regeneración en un discurso en 1869; como se podría creer, no fue Rafael Núñez, liberal moderado y líder de la Regeneración, quien inventó este vocablo ${ }^{38}$.

35 Alberto Urdaneta, "Constitución de Rionegro: art 91", Biblioteca Nacional de Colombia, https:// catalogoenlinea.bibliotecanacional.gov.co/client/es_ES/search/asset/22232/0.

36 Javier Mejía Cubillos, Diccionario biográfico y genealógico de la élite antioqueña y viejocaldense. Segunda mitad del siglo XIX y primera del XX (Pereira: Red Alma Mater, 2012), 102, https://www. researchgate.net/publication/278728620_Diccionario_Biografico_y_Genealogico_de_la_Elite_ Antioquena_y_Viejocaldense_Segunda_Mitad_del_Siglo_XIX_y_Primera_Mitad_del_XX.

37 Rufino Gutiérrez Isaza, "Reminiscencias", El Comercio, 28 de febrero de 1885, 1, http://babel. banrepcultural.org/digital/collection/p17054coll26/id/5463.

38 Otero, Historia del periodismo, 109. 
Los liberales estaban divididos dentro de su mismo partido, la presión que los conservadores e incluso los liberales moderados empezaron a hacer generó un llamado dentro de los círculos liberales a mantener la unión, como el periódico La Situación de Panamá, de tendencia liberal, escribió en su primer número en 1876, reflejando un contexto donde los liberales en el poder empezaban a sentir una amenaza latente hacia su gobernanza: "Fundamos esta hoja periódica para defender al partido liberal, para defender las instituciones que nos rijen i para abogar por la causa del orden, del progreso i de la libertad"39. Adentro del núcleo conservador también existían divisiones, pero no eran tan profundas como las liberales, además, los conservadores tenían una meta en común que los unía y encarrilaba: sacar a los liberales radicales del poder. Los liberales mantenían su afrenta contra un partido altamente religioso, que utilizaba el catolicismo y a Dios no solo como elementos de identificación, sino también como lanzas con las cuales atacar a los "rojos", puesto que los conservadores se indignaron y guardaban resentimiento ante la ley de manos muertas que le quitó y expropió a la Iglesia terrenos, propiedades y dinero que personas que habían muerto le habían dejado al clero. La Situación era consciente del peso de la religión para el pueblo colombiano y del poder que obtenía el Partido Conservador al tener los mismos intereses y ser aliado de la Iglesia católica:

La oposición liberal ha perdido su razón de ser en las actuales circunstancias, en que cada cual debe poner su pequeño óbolo, para salvar la república del retroceso a que quiere condenarla el partido de las tradiciones, de los concilios i de los Papas, cuyo hecho es tan claro i evidente, que los más agraviados i exaltados oposicionistas reconocen la necesidad de combatir la irrupción monacal que amenaza la república ${ }^{40}$.

Marco Antonio Estrada, presidente del Estado soberano de Santander en 1876 y una de las figuras más prominentes del radicalismo santandereano ${ }^{41}$, publicó en una hoja suelta dentro de un periódico en tiempos de la "guerra santa" o de las "escuelas" donde anota que,

Algunos de nuestros compatriotas con el prestesto de defender la relijion de Jesucristo, que es la del pueblo colombiano, i que por lo mismo nadie ataca en el país, han levantado el estandarte de la rebelión en el Estado soberano del Cauca. [...] El Gobierno de la Unión, guiado por un sentimiento paternal, ha cedido a las exigencias del clero hasta donde sus deberes para con la Nación lo han permitido, con el laudable fin de evi-

39 M. R. De la Torre e Hijos, "Prospecto" y "La oposición”, La Situación, 29 de octubre de 1876, 1, https://catalogoenlinea.bibliotecanacional.gov.co/client/es_ES/search/asset/160470/0.

40 Ibid.

41 Lina Constanza Díaz Boada, "Consolidación y declive de una generación política en el siglo XIX: a propósito de la trayectoria de Marco Antonio Estrada Plata", Anuario de Historia Regional y de las Fronteras,.$^{\circ} 14$ (2009): 275. 
tar una lucha armada, insostenible en el presente siglo, de funestas consecuencias para la civilización del pueblo i para esa misma relijion, que no puede hacer prosélitos sino al amparo del humano i filosófico principio de la tolerancia, de respeto a las creencias individuales; mas los enemigos jurados del orden no se han detenido en sus criminales intentos, i prosiguen llevando a la matanza a sus creyentes ${ }^{42}$.

Las tensiones liberales y conservadoras, como hemos visto, giraban en torno a diferentes puntos, la Constitución de 1863 y la relación Iglesia-Estado, por nombrar las más notables. Los conservadores acusaron a los liberales de odiar la religión y de atacar la Iglesia de manera directa con sus leyes y constitución, mientras que los liberales respondieron que el catolicismo es la religión de los colombianos, sin embargo, sostenían que las creencias individuales deben ser respetadas, y por ende un Estado laico sería la mejor opción. En un video-ensayo, Natalie Wynn analiza la cultura de la vergüenza ajena y esboza elementos que pueden ser útiles para entender este conflicto. La sátira y el humor encontrados en las caricaturas, así como ese tipo de deshumanización e incluso zoomorfización del "otro" político o del "enemigo" sirven como lo que Wynn denomina, traduciendo literalmente del inglés, "mascotización", que consiste en escoger a una persona y nombrarla líder y representante absoluta de un grupo social, y en este caso político, exagerando sus características físicas, morales, religiosas y personales, generando una burla o una mofa en la que burlarse del líder es consecuentemente una burla a sus seguidores; es un proceso de selección de rasgos y momentos que "definen" al enemigo y su vida, esto puede llevar a la ridiculización y a que los espectadores se identifiquen con la persona satirizada por "vergüenza ajena" o sentir repulsión hacia el personaje representado ${ }^{43}$. Reconocer en sí mismo uno de los rasgos o pensamientos de los que una comunidad se ríe o caricaturiza puede ser un factor crucial para cambiar de opinión, ya sea política o de cualquier otra índole. A esto se refiere Rodríguez Vargas cuando menciona que la prensa fue una de las constructoras del "imaginario nacional", de la identidad colectiva y del enemigo colectivo:

[...] las fuentes pictóricas arrojan una serie de pistas para la comprensión sobre cómo se forman los grandes imaginarios nacionales; con ello, la representación de un orden social que incluye y excluye sujetos; un orden marcial, que se idealiza o puede ser puesto en cuestión; un orden temporal que implica una doble relación, desde el pasado y el presente, con el futuro nacional ${ }^{44}$.

42 Marco A. Estrada (presidente del Estado de Santander), “Alocución”, Boletín Oficial, 6 de agosto de 1876, 1, http://babel.banrepcultural.org/digital/collection/p17054coll26/id/3799.

43 Natalie Wynn (Contrapoints), “Cringe”, video de YouTube, 10 de mayo del 2020, https://www.youtube. com/watch?v=vRBsaJPkt2Q\&has_verified=1\&ab_channel=ContraPoints.

44 Hernán Rodríguez Vargas, "Cultura visual y guerras civiles. Continuidades y contradicciones nacionales, Colombia 1871-1885”, Memoria y Sociedad 22, n. 44 (2018): 79, https://doi.org/10.11144/Javeriana. 
Se logran leer en la prensa y en la caricatura política ciertos intereses y motivos específicos que tuvieron los actores políticos para escribir lo que escribieron y dibujar lo que dibujaron. La Iglesia, la constitución, la corrupción y el “dictador” son conceptos bastante dicientes que, más allá de recontar la realidad, nos muestran cómo un sector específico la entendió y cómo la representó después para crear una narrativa que se ajustara a sus intereses y fines. Esto no es algo exclusivo de los conservadores, ya que los liberales hicieron lo mismo, sin embargo, en los Estados Unidos de Colombia los conservadores, con el apoyo de la Iglesia, tomaron el papel de la oposición, ya que su partido no estaba en la gobernanza, lo que permite leer los artículos de la prensa y la caricatura como intentos por recuperar el poder. El imaginario social y nacional no era incluyente con todos sus habitantes y constantemente se luchaba por erigir héroes de la patria y sus correspondientes villanos: "Se lograron evidenciar los imaginarios del orden social nacional y el orden hegemónico que consagra a unos como héroes y próceres, subordina a otros — los soldados - , y marginaliza o excluye a otros, por lo general: mujeres, campesinos, indígenas y negros"45.

Existe, entonces, la representación oficial, avalada por el Gobierno, y la no-oficial, que se contrapone a la visión oficial y representa otra cara de los hechos. Este tipo de reproducciones demuestran el contraste entre los proyectos nacionalistas y las rupturas de la nación como comunidad imaginada, los matices sociales, políticos, económicos y raciales que prevalecieron en el siglo XIX colombiano; además, se demuestra la crisis del modelo nacional y patriótico como comunidad imaginada cuando se estudian los conflictos entre partidos y las guerras civiles a través de la prensa y la caricatura ${ }^{46}$. Es entonces posible leer la guerra por el poder no solo en el campo de batalla, sino también en los periódicos, hojas sueltas y caricaturas que circularon durante los Estados Unidos de Colombia, donde el "enemigo" de la fe y de la moral tenía unos símbolos y signos específicos que permitían hacer juicios morales y de valor a priori. Reírse del adversario es una táctica política que le permite a la comunidad reírse en conjunto de rasgos inaceptables; esta acción en comunidad va cambiando el rumbo de un país.

\section{Conclusiones}

“[...]Primero, caricatura colombiana es un pleonasmo, puesto que todo lo colombiano de la nueva Colombia es caricatura, Colombia inclusive. Segundo, la caricatura, pues, ya está hecha. Siguiendo esa lógica se podría afirmar que la historia de la caricatura es la Historia de Colombia, y que la historia de la Historia de la caricatura es la Historia patria" ${ }^{47}$. 
Estudiar la prensa y la caricatura en el siglo XIX colombiano presenta diferentes aristas y matices que generan un debate rico y complejo, y permite leer la historia nacional y el presente político como conflictos de larga duración. Aunque el Partido Liberal no mantuvo las características e ideologías que tuvo en el siglo XIX, se pueden encontrar en el presente las mismas tensiones sobre la religión y el Estado, la corrupción, los dictadores y demás construcciones en la opinión pública. Los liberales y conservadores vivieron una lucha y una crisis constante en los Estados Unidos de Colombia y durante todo el siglo XIX por controlar el aparato institucional y la constitución, que permitía el dominio del territorio, la economía, la población y sobre lo que es legítimo, entre otras cosas. Esta lucha no solo se llevaba a cabo en las guerras civiles, también en la prensa y en las representaciones pictóricas como la caricatura se puede leer entre líneas una constante tensión por obtener el poder y la gobernanza.

Las críticas conservadoras se centraron en diferentes puntos: la relación Iglesia-Estado y la representación de los liberales como enemigos y atacantes de la religión católica con sus leyes, la Constitución de 1863 como un documento que era un obstáculo para los ideales conservadores y que debía ser reescrito tan pronto como fuese posible, los líderes liberales fueron representados como villanos, tiranos y dictadores, así como el grupo de los "sapos", pues eran asociados por los conservadores con el fraude y la corrupción. La identidad política colombiana fue un factor de violencia que sobrevive hasta el día de hoy; atacar la religión, las visiones y la idea de gobernar el país nunca ha sido una acción pasiva y calmada de debate político, especialmente en Colombia; ser parte de "los rojos" o de "los azules" conllevaba ciertas cargas ideológicas específicas, una identidad, cargas de violencia y una visión del "otro" como un enemigo que no debía subir al poder. Esta lucha es el antepasado de la persecución política que continuó durante el siglo XX colombiano. Incluso podemos verlo en el siglo XXI, donde la izquierda sigue siendo asociada a rótulos escritos por la lucha del siglo XIX.

Este tipo de representaciones tuvieron un fin específico que fue aportar a la lucha conservadora por retomar el poder y las "riendas" del país. A través del humor, la mofa y la sátira se empezó a construir un imaginario nacional y se pretendió moldear la opinión pública de un sector específico de la sociedad colombiana, de las personas letradas, que podían votar, que en el siglo XIX cerró el debate de la prensa a hombres generalmente blancos, de élite y de cierto estatus social, quienes escribían en periódicos y hojas sus visiones políticas. Esta campaña conservadora en la prensa y caricatura pudo haber influido en la Regeneración, ya que desde las elecciones de 1878 empezaron a ganar liberales moderados y el conservatismo lentamente volvió a obtener la gobernanza del país.

de YouTube, 15 de enero del 2010, https://www.youtube.com/watch?v=POwwGH9wkqc. 


\section{Referencias}

\section{Primarias}

“Constitución Política 1 de 1863". Asamblea Nacional Constituyente, https://www. funcionpublica.gov.co/eva/gestornormativo/norma.php?i=13698.

“Constitución Política 1 de 1886". Asamblea Nacional Constituyente, https://www. funcionpublica.gov.co/eva/gestornormativo/norma.php?i=7153.

De la Torre, M. R. "Prospecto" y "La oposición". La Situación, 29 de octubre de 1876, https://catalogoenlinea.bibliotecanacional.gov.co/client/es_ES/search/ asset/160470/0.

Estrada, Marco Antonio. "Alocución". Boletín Oficial, 6 de agosto de 1876, http:// babel.banrepcultural.org/digital/collection/p17054coll26/id/3799.

Gutiérrez Isaza, Rufino. "Reminiscencias". El Comercio, 28 de febrero de 1885, http:// babel.banrepcultural.org/digital/collection/p17054coll26/id/5463.

"Los Dos Altos Poderes Nacionales en 1867. Historia". Los Locos, 29 de abril de 1868, http://babel.banrepcultural.org/cdm/compoundobject/collection/p17054co1126/id/2096/rec/1.

"Otra pregunta". Los Locos, 18 de junio de 1868, http://babel.banrepcultural.org/digital/collection/p17054coll26/id/1903.

Pérez, Pedro. "Carta”. Los Locos, 9 de mayo de 1868, http://babel.banrepcultural.org/ digital/collection/p17054coll26/id/1912.

Pontón, Nicolás. "Cúlpense a sí mismos". Los Locos, 18 de junio de 1868, http://babel.banrepcultural.org/digital/collection/p17054coll26/id/1903.

"Primera Perorata de prejuicios". Los Locos, 18 de marzo de 1868, http://babel.banrepcultural.org/digital/collection/p17054coll26/id/1905.

Urdaneta, Alberto. "Constitución de Rionegro", Bogotá, 1876, BNC, https://catalogoenlinea.bibliotecanacional.gov.co/client/es_ES/search/asset/22232/0. 
Urdaneta, Alberto. "Lo que debería ser", Bogotá, entre 1863-1885, BNC, https://catalogoenlinea.bibliotecanacional.gov.co/client/es_ES/search/asset/22227/0.

Urdaneta, Alberto. “Tomás Cipriano de Mosquera: 1792?-1877”, Bogotá, 1877, Biblioteca Nacional de Colombia (BNC), https://catalogoenlinea.bibliotecanacional.gov.co/client/es_ES/search/asset/98321/0.

\section{Secundarias}

Acevedo Carmona, Darío. "La caricatura política y la violencia liberal-conservadora". Credencial Historia, n. ${ }^{\circ} 125$. https://www.banrepcultural.org/biblioteca-virtual/credencial-historia/numero-125/la-caricatura-politica-y-la-violencia-liberal-conservadora.

Banrepcultural. "Beatriz González - La historia de la historia de la caricatura en Colombia (1/8)". Video de YouTube, publicado el 15 de enero del 2010, https:// www.youtube.com/watch?v=POwwGH9wkqc.

Banrepcultural. "Beatriz González - La historia de la historia de la caricatura en Colombia (9/9)". Video de YouTube, publicado el 15 de enero del 2010, https:// www.youtube.com/watch?v=4WWbjZcWoqA\&ab_channel=BanrepculturalBanrepcultural.

Basilien-Gainche, Marie-Laure. "La constitucionalidad de contienda: la promoción jurídica de la guerra civil en la Colombia del siglo XIX". Historia Crítica, n. ${ }^{\circ}$ 35 (2008): 130-149.

Cacua Prada, Antonio. Historia del periodismo colombiano. Bogotá: Fundación El Libro Total, 1968. https://www.ellibrototal.com/ltotal/?t=1\&d=7826.

Díaz Boada, Lina Constanza. "Consolidación y declive de una generación política en el siglo XIX: a propósito de la trayectoria de Marco Antonio Estrada Plata". Anuario de Historia Regional y de las Fronteras, n. ${ }^{\circ} 14$ (2009): 273-301.

González, Beatriz. "La caricatura en Colombia a partir de la independencia". Banrepcultural. https://www.banrepcultural.org/la-caricatura-en-colombia/texto01.html.

Jurado, Juan Carlos. "La zoociedad antioqueña en los siglos XVIII y XIX”. Credencial Historia, n. ${ }^{\circ} 97$. https://www.banrepcultural.org/biblioteca-virtual/credencial-historia/numero-97/la-zoociedad-antioquena-en-los-siglos-xviii-y-xix. 
Mejía Cubillos, Javier. Diccionario biográfico y genealógico de la élite antioqueña $y$ viejocaldense. Segunda mitad del siglo XIX y primera del XX. Pereira: Red Alma Mater, 2012. https://www.researchgate.net/publication/278728620_Diccionario_Biografico_y_Genealogico_de_la_Elite_Antioquena_y_Viejocaldense_Segunda_Mitad_del_Siglo_XIX_y_Primera_Mitad_del_XX.

Murcia Sánchez, Fernando. "Imprenta e institucionalización: la cultura letrada en las imprentas de José Antonio Cualla y Nicolás Pontón". (Proyecto a la investigación en Historia Colonial, ICANH, 2013. https://www.icanh.gov.co/nuestra_entidad/grupos_investigacion/grupo_historia_colonial_republicana/resultados_proyectos_investigacion_6472/8428\&download=Y.

Orrego Penagos, Juan Luis, "Liberales y conservadores en el siglo XIX: Un viejo debate". Historia Caribe 3, n. 8 (2003): 69-80. https://www.redalyc.org/ pdf/937/93700806.pdf.

Otero Muñoz, Gustavo. Historia del periodismo en Colombia. Bogotá: Universidad Sergio Arboleda, 2019. https://es.calameo.com/read/006431485ab8c4 ce 14268 .

Rodríguez-Arenas, Flor María. Bibliografía de la Literatura Colombiana del siglo XIX, Tomo 2 M-Z. Bogotá: Stock-cero, 2006. https://www.stockcero.com/ pdfs/978-987-1136-47-6_SAMP.pdf.

Rodríguez Vargas, Hernán. "Cultura visual y guerras civiles. Continuidades y contradicciones nacionales, Colombia 1871-1885". Memoria y Sociedad 22, n. ${ }^{\circ} 44$ (2018): 66-81. https://doi.org/10.11144/Javeriana.mys22-44.cvgc.

Ruiza, M., T. Fernández y E. Tamaro. "Biografía de Alberto Urdaneta”. Biografias y Vidas. La enciclopedia biográfica en línea. https://www.biografiasyvidas.com/ biografia/u/urdaneta_alberto.htm.

Samacá, Gabriel. "Prensa y divulgación de la historia patria en Colombia: la obra de Pedro María Ibáñez en publicaciones literarias e ilustradas, 1882-1919". Co-herencia 16, n. ${ }^{\circ} 31$ (2019): 323-355. https://doi.org/10.17230/co-herencia.16.31.10.

Vallejo Murcia, Olga, Ana María Agudelo Ochoa y Xiomara Meneses Cano. "Publicaciones seriadas de la literatura colombiana. Fuentes periódicas para el estudio histórico de la literatura colombiana. Compilación y reseña. Primera 
entrega". Estudios de Literatura Colombiana, n. ${ }^{\circ} 28$ (2011): 159-177. https:// dialnet.unirioja.es/descarga/articulo/3876295.pdf.

Wynn, Natalie (Contrapoints). "Cringe". Video de YouTube, publicado el 10 de mayo de 2020. https://www.youtube.com/watch?v=vRBsaJPkt2Q\&has_verifie$\mathrm{d}=1 \& \mathrm{ab} \_$channel $=$ContraPoints. 